\title{
Two-component micro injection moulding for hearing aid applications
}

Islam, Aminul; Hansen, Hans Nørgaard; Marhöfer, David Maximilian; Angel, Jais Andreas Breusch; Dormann, B.; Bondo, M.

Published in:

International Journal of Advanced Manufacturing Technology

Link to article, DOI:

10.1007/s00170-011-3841-1

Publication date:

2012

Link back to DTU Orbit

Citation (APA):

Islam, A., Hansen, H. N., Marhöfer, D. M., Angel, J. A. B., Dormann, B., \& Bondo, M. (2012). Two-component micro injection moulding for hearing aid applications. International Journal of Advanced Manufacturing Technology, 62(5-8), 605-615. https://doi.org/10.1007/s00170-011-3841-1

\section{General rights}

Copyright and moral rights for the publications made accessible in the public portal are retained by the authors and/or other copyright owners and it is a condition of accessing publications that users recognise and abide by the legal requirements associated with these rights.

- Users may download and print one copy of any publication from the public portal for the purpose of private study or research.

- You may not further distribute the material or use it for any profit-making activity or commercial gain

- You may freely distribute the URL identifying the publication in the public portal 


\title{
Two component micro injection moulding for Hearing Aid applications.
}

\author{
A. Islam ${ }^{1}$, H. Hansen ${ }^{1}$, M. Marhöfer ${ }^{2}$, J. Angel ${ }^{1}$, B. Dormann ${ }^{3}$, M. Bondo ${ }^{2}$ \\ ${ }^{1}$ Department of Mechanical Engineering, Technical University of Denmark. \\ ${ }^{2}$ SONION A/S, Roskilde, Denmark. \\ ${ }^{3}$ DESMA GmbH, Desmastr, Achim, Germany.
}

\begin{abstract}
Two component (2k) injection moulding is an important process technique at the present state of technology and it is growing rapidly in the field of precision micro moulding. Besides combining different material properties in the same product, two component moulding can eliminate many assembly steps in the manufacturing process chain. One of the biggest technical challenges associated with $2 \mathrm{k}$ moulding is the unavailability of suitable material combinations which can meet the diverse requirement from both product and process point of views. When it comes to the point of micro application, the precise dimensional requirement and tolerance makes the $2 \mathrm{k}$ moulding a technically challenging process. This paper presents an industrial case study of $2 \mathrm{k}$ micro moulding covering all the important issues like product design, material selection, moulding and functionality testing of the micro moulded $2 \mathrm{k}$ parts. An intensive search for suitable $2 \mathrm{k}$ materials are made and few combinations of plastic materials are presented in the paper which can be used for highly demanding application areas like hearing aids. By using these material combinations, a demonstrator $2 \mathrm{k}$ micro part has been fabricated. The moulding machine was a state-of-the-art $2 \mathrm{k}$ micro machine from DESMA. The fabricated micro part was a socket house integrated with a sealing ring for the Receiver-In-Canal (RIC) hearing instrument. The test performed on the demonstrator showed the potential of the $2 \mathrm{k}$ moulding technology to be able to solve some of the exiting problems associated with hearing instruments.
\end{abstract}

\section{Key words}

Two component injection moulding, RIC socket, sealing ring. 


\section{Introduction}

Two component injection moulding is a unique process technique that combines two different plastic materials in the same product. The widespread use of the technology started during 1980s. Since then the market has been exploded and today there are ordinary toys, tooth brushes, tool handles etc. all manufactured with $2 \mathrm{k}$ technology. The technology can also be found in the specialized areas like the telecom, automotive, packaging, medical technologies etc. More and more products are being redesigned at present to harvest the full advantage provided by two component moulding.

But when it comes to the point of micro moulding, $2 \mathrm{k}$ process imposes great challenges even at the present state of technology. In strongly adhering materials combinations, two different plastics form an interface zone where two materials melt and mix together [1]. For micro $2 \mathrm{k}$ moulding this interface zone can be bigger than the dimension of the part or some features in the part. This possesses a big challenge for many well-known combinations of plastic materials to be used in $2 \mathrm{k}$ micro moulding. Micro parts have relatively higher surface area to volume ratio which changes the heat transfer characteristics, wettability and mechanical behavior of the part [1]. All these points together make $2 \mathrm{k}$ micro moulding more complex compared to the $2 \mathrm{k}$ macro scale moulding.

This paper presents the results from experimental investigation to prove the feasibility of using $2 \mathrm{k}$ micro moulding process for precision application. The feasibility test is carried out with a newly developed micro $2 \mathrm{k}$ machine and by using some unconventional pairs of plastic materials. The part design, material selection and moulding process are optimized so that the process chain can successfully produce the demonstrator parts and the whole production chain is discussed in the paper. Besides this, the paper introduces a new Receiver-In-Canal (RIC) socket for hearing aid applications which can potentially overcome some critical problem of the corresponding existing product.

\section{Demonstrator product}

The chosen demonstrator product for this investigation is a RIC socket for RIC hearing aid system. RIC hearing aid refers to a BTE (Behind the Ear) hearing aid where the receiver (loudspeaker) is placed outside the hearing aid body. A thin-wire that is insulated in a thin-tube connects the receiver with the rest of the hearing aid body. The mechanism that connects the hearing aid body with the hearing aid receiver is called a RIC connector and it is usually comprised of a combination of a plug and a socket (See Figure 1). RIC connector is the enabling technology behind the recent boost in BTE hearing aid which combines the benefit of BTE and CIC (completely in the canal) hearing aid systems [2]. RIC hearing aid is more stylish, more esthetically appealing and functionally versatile than traditional BTE hearing aid system. 


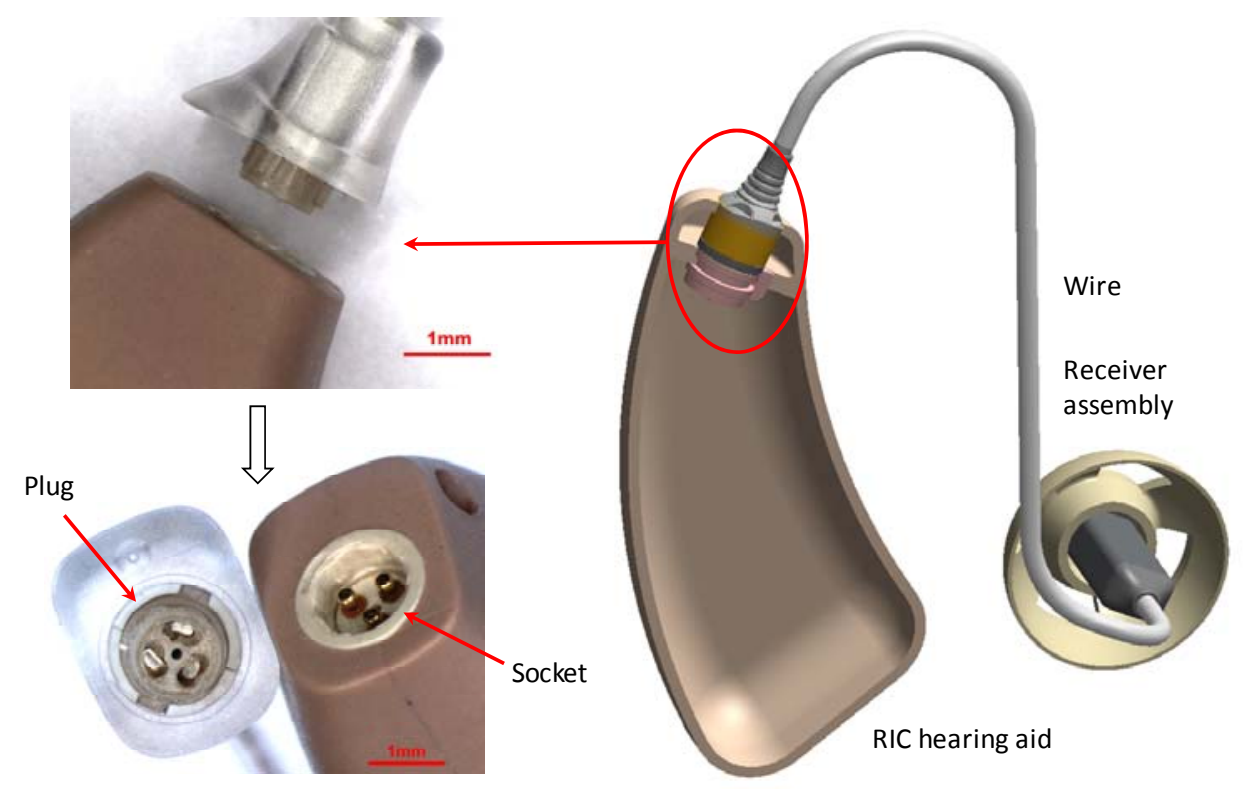

Figure 1: Schematic representation of RIC hearing aid and RIC connector (plug and socket).

The main problem associated with the RIC connector today is the inadequate sealing between the plug and socket which allows sweat, moisture, dirt and other foreign particles to get inside the socket house and initiate corrosion with the inner metallic components of the RIC system. Subsequently the connection between plug-socket is hindered and the hearing aid cannot work anymore. To overcome this problem a new design of RIC socket is proposed in the current paper with an integrated sealing ring to protect the inner metallic components of the RIC connector.

An O-ring or sealing ring is torus or doughnut-shaped ring usually moulded with elastomeric materials and can prevent the loss of a fluid or gas from a system [3]. In this paper the term sealing ring is used for a part which is moulded from elastomeric materials and used as a prevention system for gaining outer fluid, gas or particles inside the closed area between plug and socket of a RIC hearing aid. Figure 2 shows the conventional design of RIC socket and new design of RIC socket with integrated sealing ring in it. The detail design of a demonstrator RIC socket combined with sealing ring is presented in Figure 5 and in Figure 6 . The paper reveals the full process chain for socket production based on this new design by two component micro injection moulding.
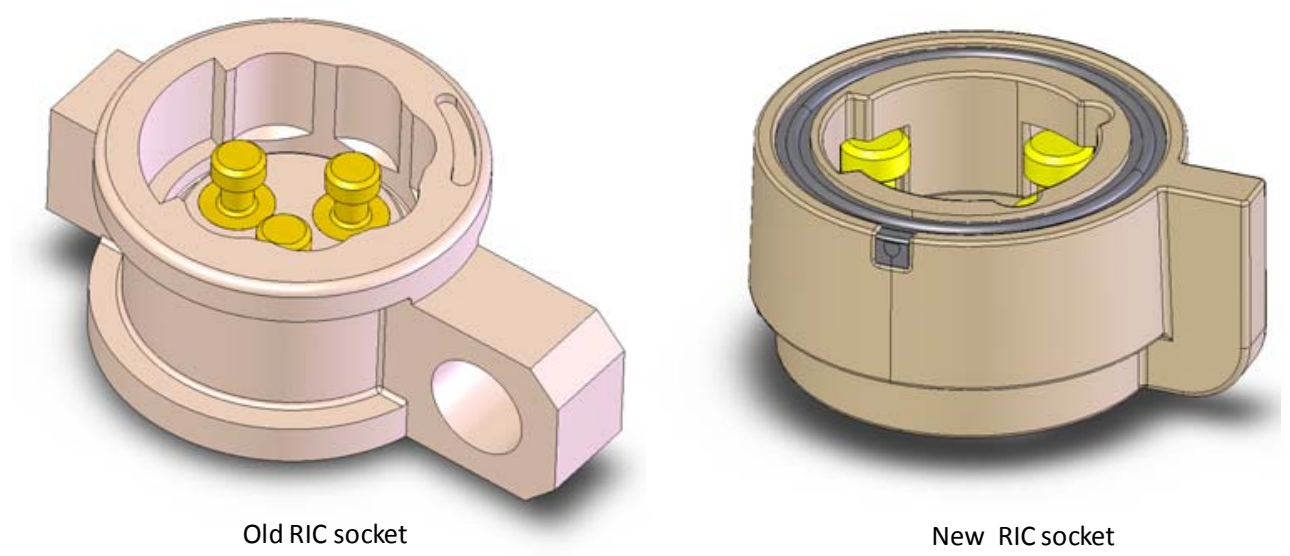

Figure 2: Hearing aid RIC socket-old RIC socket (left picture) and new RIC socket design (right picture). 


\section{Two component machine used in the investigation}

The moulding machine used for this experiment was a newly developed $2 \mathrm{k}$ micro moulding machine from DESMA. The Formica Plast has two phase injection unit and uses a screwless injection system to plasticize and inject the plastic materials into the mould cavity. Shot weight ranging from 10 to $400 \mathrm{mg}$ is possible to produce with this machine [4].

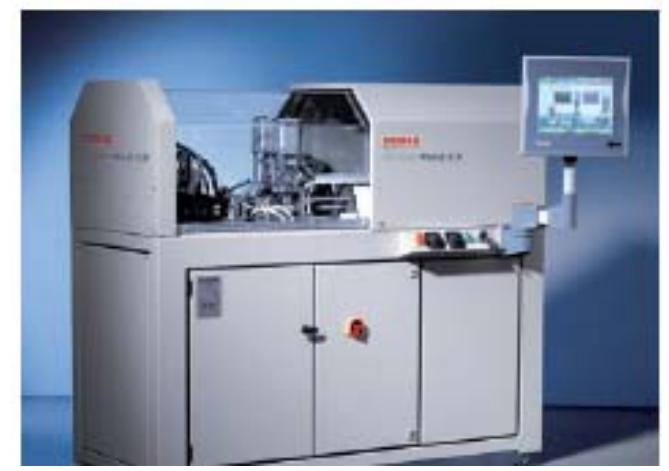

FormicaPlast $2 \mathrm{k}$ machine

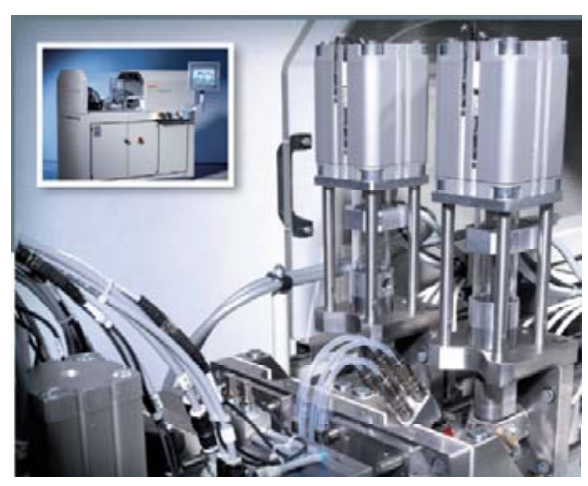

FormicaPlast 2k injection unit

Figure 3: Formic Plast 2k micro injection moulding machine (left picture), two parallel injection unit of Formica Plast machine (right picture) [4] .

In Formica Plast the pre-plastification is realized by a $6 \mathrm{~mm}$ piston with the heat from the heater band and a $3 \mathrm{~mm}$ piston is used for high precision injection of material in to the mould cavity (see Figure 4). The machine uses a simple transfer index mechanism to switch between the shots. After the first shot mould is opened, the inserts are raised out of the mould plates by forward motion of the rotary arm and rotated through $180^{\circ}$ to get to the new injection position. The transfer from the first position to the second position takes only $0.2 \mathrm{sec}$.
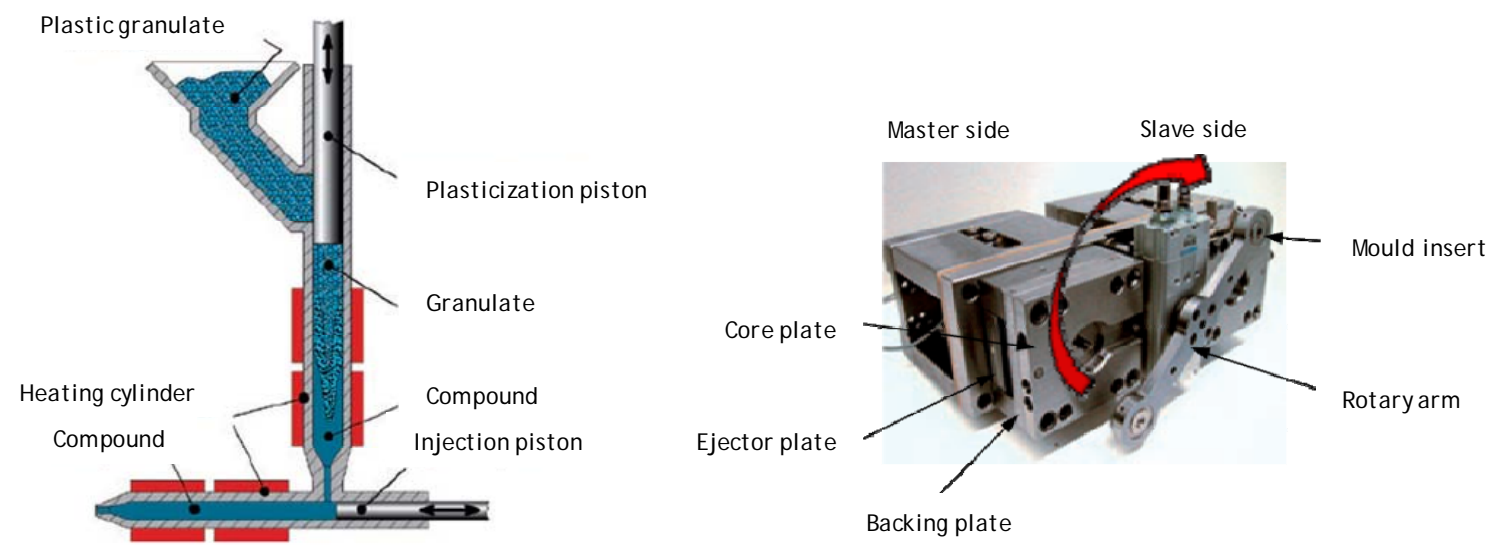

Figure 4: Schematic representation of injection unit of Formica Plast $2 k$ machine from DESMA (left picture) and transfer index mechanism for $2 k$ moulding in Formica Plast machine (right picture) [5]. 


\section{Experimental investigation}

The objective of this experiment is to design, optimize and produce the hearing aid RIC socket integrated with the sealing ring by the use of a state-of-the-art $2 \mathrm{k}$ machine and to test the feasibility of using a moulded sealing ring for precision application. The materials selection and process optimization for micro $2 \mathrm{k}$ moulding are conducted in the current experimental investigations.

\subsection{Part geometry}

As mentioned before the test part for this investigation was the new design of hearing aid RIC socket and the most significant design improvement is the integration of a sealing ring to provide sufficient sealing after the socket is connected with the plug. The commons cross section design for a sealing design would be a circular cross section. The conventional way to produce the $2 \mathrm{k}$ socket would be separately produced socket house and sealing ring assembled together. In the current case the chosen production method is $2 \mathrm{k}$ moulding to eliminate the need for separate assembly operation. To facilitate the $2 \mathrm{k}$ moulding process, the part design needs some adjustment (schematically presented in Figure 5). In the modified design the circular cross section of the sealing ring is replaced with a square shape to ease the tooling operation and an inlet (injection point) is made in the socket house so that the second material (sealing ring material) can be injected after the injection of first material. The detailed design and dimensional specifications of the new RIC socket are presented in the Figure 6.

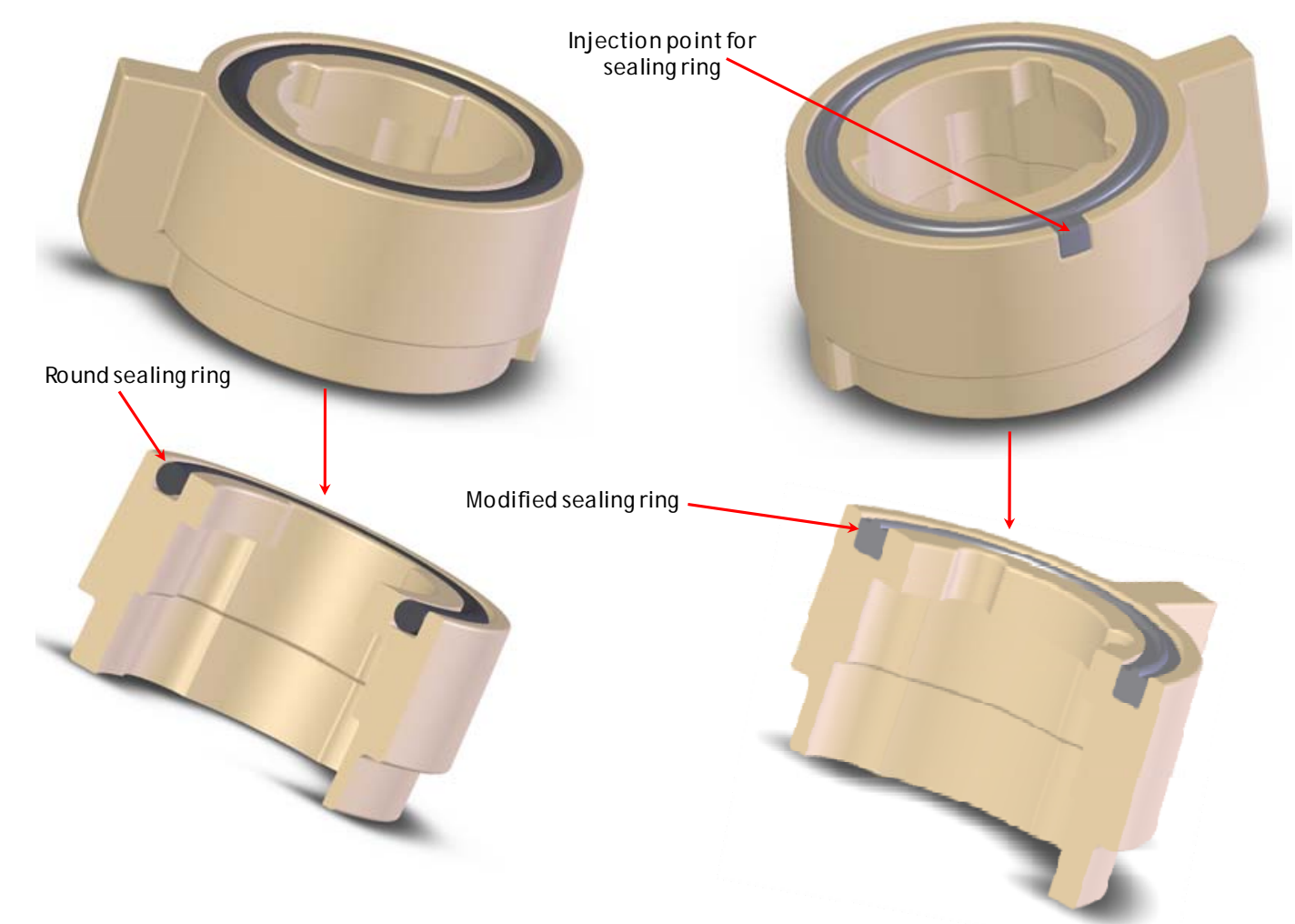

Figure 5: New socket design integrated with a sealing ring - socket design based on conventional sealing ring and assembly (left pictures) and modified socket design based on $2 k$ micro moulding (right pictures). 

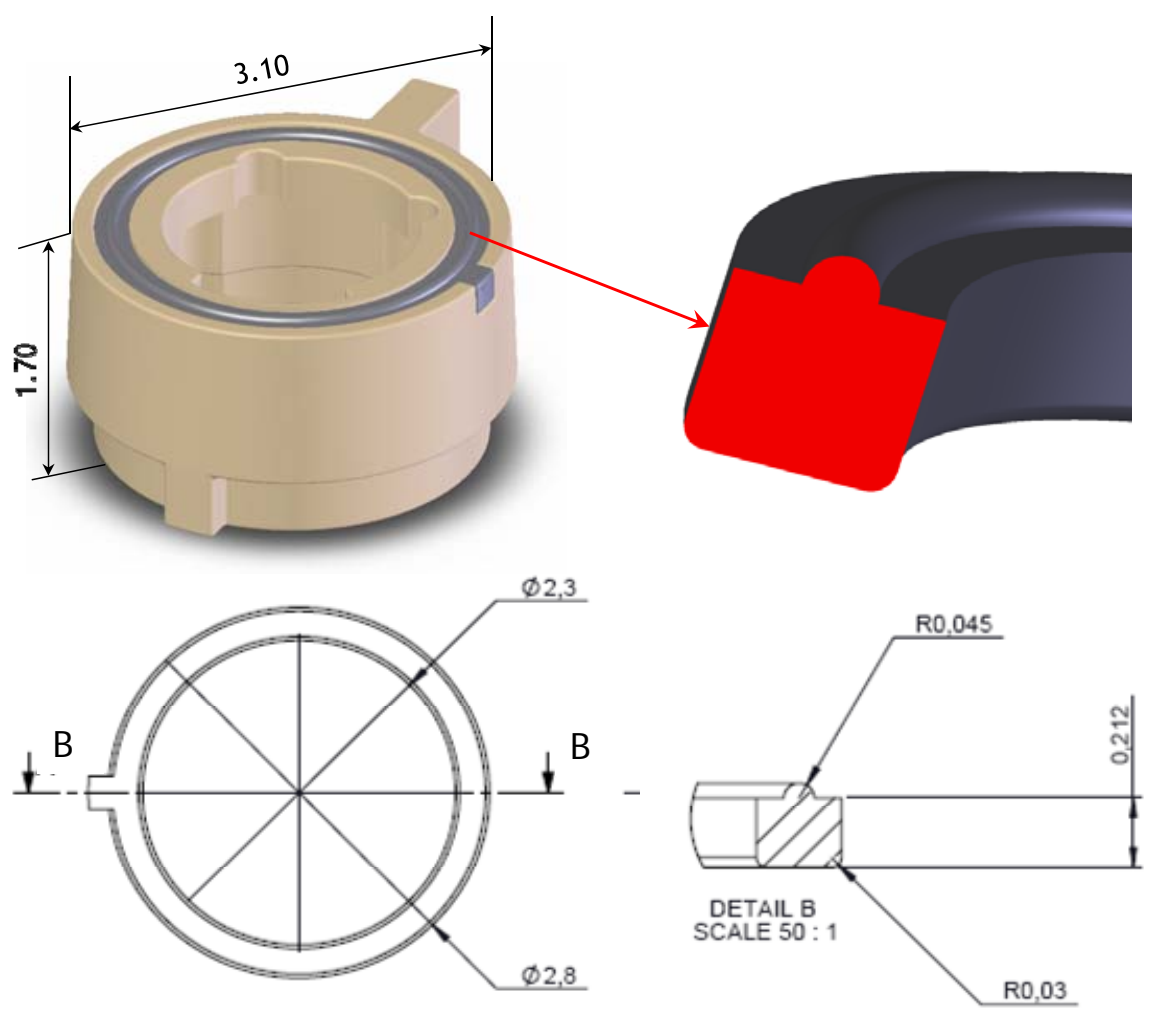

Figure 6: Schematic representation and dimensional specifications of new socket based on $2 k$ production concept (All dimensions in the picture are in $\mathrm{mm}$ ).

\subsection{Plastic materials}

Material selection is crucial for hearing aid application. Micro moulding requires special plastic materials and when it comes to the point of micro $2 \mathrm{k}$ moulding, the materials pair for $2 \mathrm{k}$ moulding should fulfil even more critical requirements. For this specific case, the two components in the final geometry would be moulded by two different plastic materials which have to fulfil many different engineering demands. The requirements to be fulfilled by selected material pairs are listed in Table 1. 
Table 1: List of requirements to be fulfilled by $2 k$ material combinations for hearing aid applications.

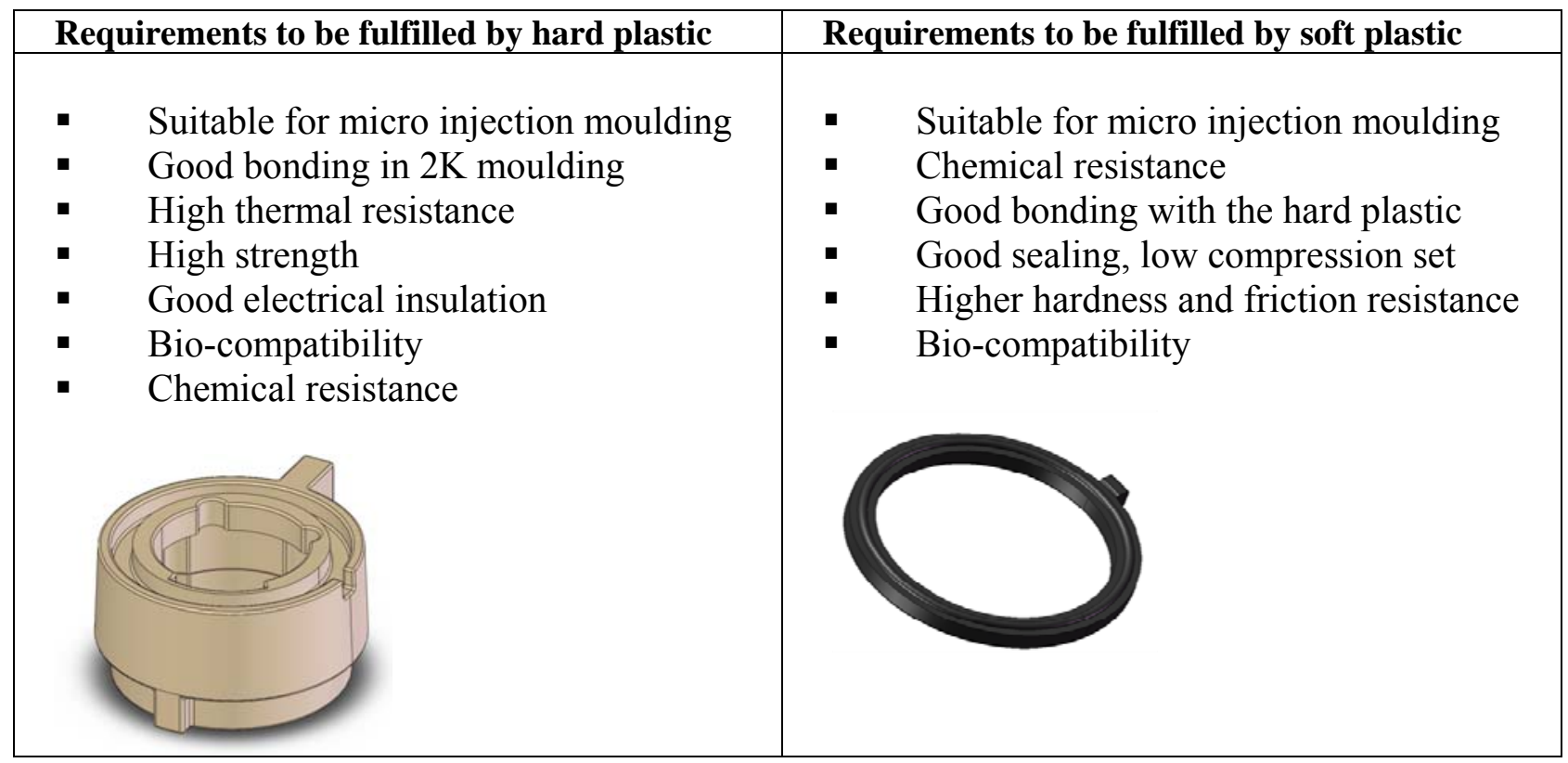

Based on the requirements mentioned in the above table following materials were selected for $2 \mathrm{k}$ moulding and tested with the selected moulding machine. The final choice of the materials would be made based on the process capabilities and functional tests performed on the moulded parts.

Table 2: List of plastic materials selected for $2 k$ moulding trial.

\begin{tabular}{|c|c|c|c|c|c|}
\hline \multicolumn{6}{|c|}{ Hard Plastic } \\
\hline No & Name & Abbreviation & Trade name & Grade & Manufacturer \\
\hline 1 & Polyetheretherketone & PEEK & Victrex & 150GL30 & Victrex \\
\hline 2 & Polyimide & PA 66 & Ultramid & A3EG10 -GF50 & BASF \\
\hline \multicolumn{6}{|c|}{ Soft Plastic } \\
\hline No & Name & Abbreviation & Trade name & Grade & Manufacturer \\
\hline 1 & Thermoplastic Elastomer & TPE & Thermolast & TC5PCZ & Kraiburg TPE, Germany \\
\hline 2 & Thermoplastic Elastomer & TPE & Lifoflex & UV56.01B038-3 & Müller Kunststoffe, Germany \\
\hline 3 & Thermoplastic Elastomer & TPE & Dryflex & A1 600602 & Elasto, Sweden \\
\hline 4 & Thermoplastic Elastomer & TPE & Thermoflex & $60 \mathrm{~A} 23-800$ & PTS, Germany \\
\hline 5 & Thermoplastic Vulcanizate & TPV & Santoprene & $8291-60 \mathrm{~B} 500$ & ExxonMobil Chemicals, USA \\
\hline
\end{tabular}

\subsection{Moulding}

Before injection moulding all the materials were dried according to the manufacturer recommendations. In the first trial of injection moulding for each material, the recommended process parameters from material manufacturers were tried and in case of bad result trials and errors were made to find the optimized parameters for the specific case of DESMA $2 \mathrm{k}$ machine and hearing aid RIC socket. The final injection moulding process parameters for different materials are listed in the Table 3. 
Table 3: Process parameters finally used in case of different materials in $2 k$ moulding.

\begin{tabular}{|l|l|l|l|l|l|l|l|}
\hline Parameters & PA66 & PEEK & $\begin{array}{l}\text { TPE } \\
\text { Thermolast }\end{array}$ & $\begin{array}{l}\text { TPE } \\
\text { Dryflex }\end{array}$ & $\begin{array}{l}\text { TPE } \\
\text { Thermoflex }\end{array}$ & $\begin{array}{l}\text { TPE } \\
\text { Lifoflex }\end{array}$ & $\begin{array}{l}\text { TPV } \\
\text { Santoprene }\end{array}$ \\
\hline Nozzle temperature $\left({ }^{\circ} \mathrm{C}\right)$ & 290 & 370 & 250 & 200 & 180 & 190 & 280 \\
\hline Plasticizing temperature $\left({ }^{\circ} \mathrm{C}\right)$ & 280 & 365 & 240 & 190 & 180 & 185 & 275 \\
\hline Cylinder temperature $\left({ }^{\circ} \mathrm{C}\right)$ & 270 & 360 & 230 & 190 & 180 & 180 & 270 \\
\hline Mould temperature (stationary half) $\left({ }^{\circ} \mathrm{C}\right)$ & 100 & 180 & 80 & 100 & 100 & 60 & 32 \\
\hline Mould temperature (moving half) $\left({ }^{\circ} \mathrm{C}\right)$ & 100 & 200 & 80 & 100 & 100 & 60 & 35 \\
\hline Injection speed $\left(\mathrm{mm}^{-\mathrm{s}}\right)$ & 100 & 500 & 150 & 200 & 100 & 150 & - \\
\hline Cycle time (S) & $\approx 7$ & $\approx 5$ & $\approx 7$ & $\approx 7$ & $\approx 7$ & $\approx 7$ & - \\
\hline
\end{tabular}

The standard sprue size of DESMA's formicaPlast machine is relatively small compared with the other standard machine. A relative comparison is presented in Figure 7. As the sprue size is smaller in case of the DESMA machine, so less material is wasted. In case of this $2 \mathrm{k}$ RIC socket the materials saving by DESMA machine is about $80 \%$, and in the long run that will be a significant saving on the price of the plastic materials.

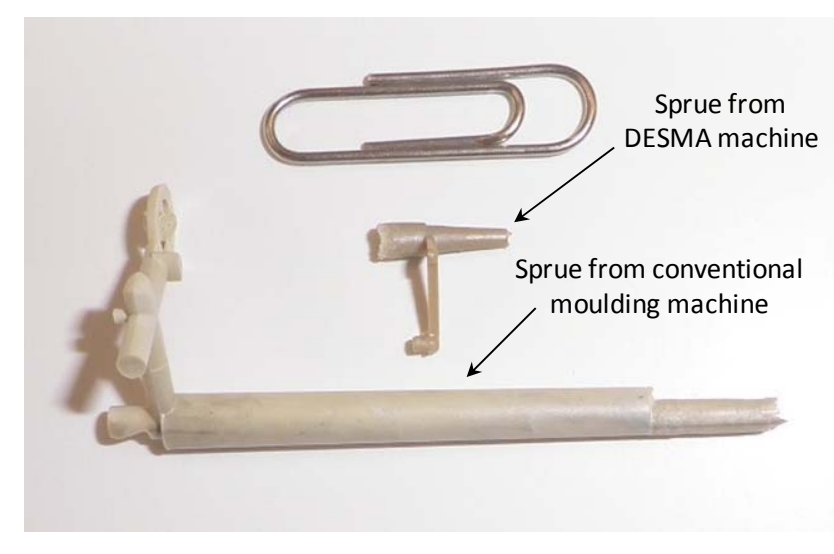

Figure 7: Comparative sprue size-smaller sprue from DESMA machine and bigger sprue from conventional injection moulding machine.

One problem encountered during the moulding trial the flash in the moulded part. The mould had some defects and flatness errors which contributed to the flash, moreover some materials had relatively lower melt viscosity which added to the flash problem. The socket was successfully moulded with Ultramid PA (for socket house) and TPE Thermolast (for sealing ring) by the $2 \mathrm{k}$ machine. The socket house was moulded in the first short and the sealing ring was moulded in the second shot. The other material combination giving an acceptable result was Ultramid PA and TPE Dryflex. Figure 8 shows the pictures of $2 \mathrm{k}$ moulded socket houses with two different material combinations. Microscopic investigation shows that both TPE materials could replicate the specific shape of the sealing ring. But the replication quality was better in the case of TPE Thermolast. 

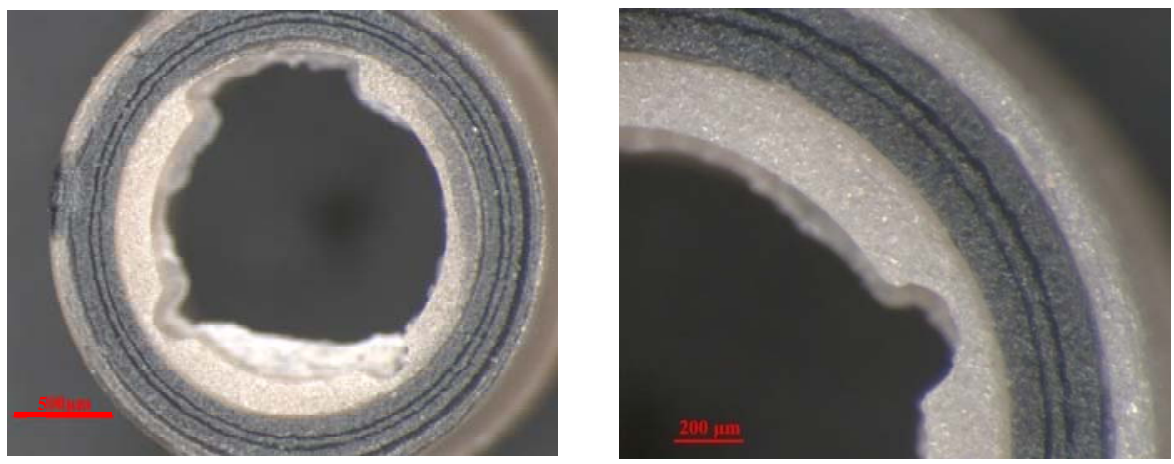

Ultramid A3EG10 \& Kraiburg TPE Thermolast TC5PCZ
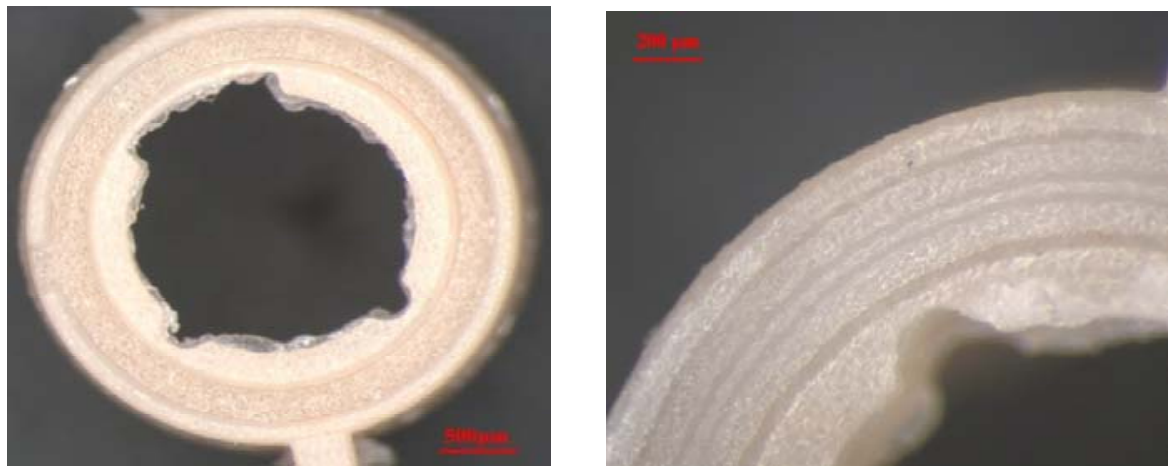

Ultramid A3EG10 \& Elasto Dryflex A1 602602

Figure 8: $2 k$ moulded socket house with two different material combinations

In case of some TPE materials the bonding with the hard plastic was poor and sealing ring was pulled off easily. Table 4 summarizes the important moulding results in case of different thermoplastic and elastomeric materials.
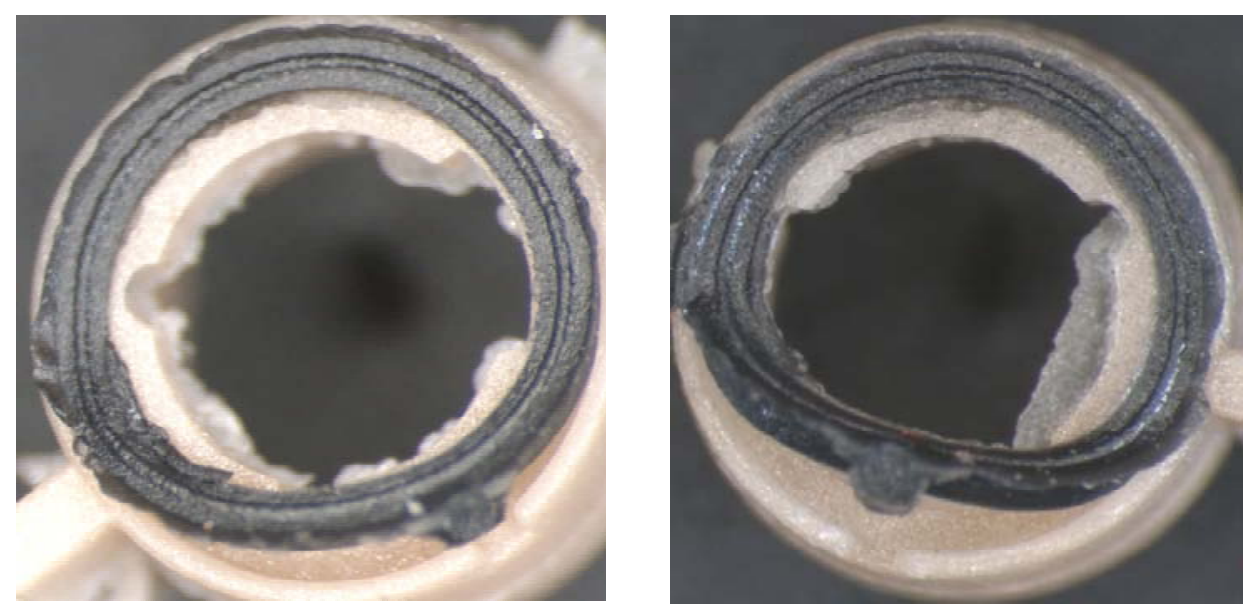

Figure 9: Example of poor adhesion between the socket house and sealing ring materials (Ultramid PA-TPE Thermoflex combination in the left picture and Ultramid PA-TPE Lifoflex combination in the right picture). 
Table 4: Moulding overview from $2 k$ moulding trial with Micro $2 k$ Formica Plast machine.

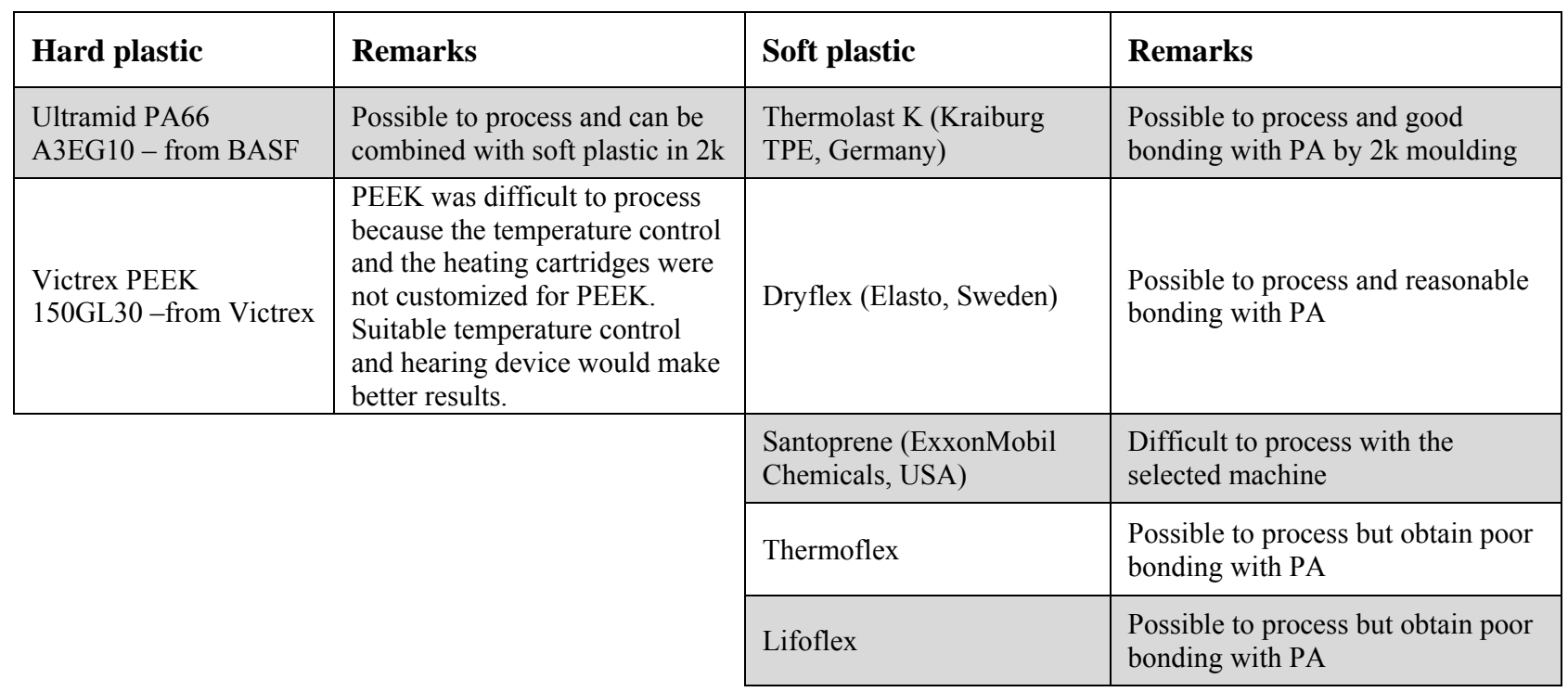

\section{Test and results}

\subsection{Bond test}

One of the important technical aspects of a two component plastic part is the bonding between the two different materials. Stronger bonding facilitates the $2 \mathrm{k}$ moulding so that the two materials stay together during the part ejection and also gives the part sufficient mechanical strength over the entire life cycle of the product. In the current product, it is important that the sealing ring does not fall out during part ejection after $2 \mathrm{k}$ moulding and does not fall off during the use of the hearing instrument either. Other than these, there is no special requirement on the bonding of the two materials. Based on the experience, the authors of this paper claim that $1 \mathrm{MPa}$ will be an acceptable bond strength in this case.

To characterize the bonding between Ultramid PA and TPE Thermolast, tensile test samples were moulded using the same process parameters used in the production of the $2 \mathrm{k}$ socket. The tensile bars were moulded in two different ways. In the first case PA was moulded with a close gate and after that the gate was opened in the mould and TPE Thermolast was moulded. This process was symmetric to the production of $2 \mathrm{k}$ socket. To compare the bond strength obtained from this, $2 \mathrm{k}$ tensile bars were also moulded with the open gate and simultaneous injection of two materials from the two different sides of the mould. Test specimens produced in these two different processes are shown Figure 10. A Mecmesin Imperial 1000 tensile testing machine was used to characterize these parts with the accompanying software Mecmesin Emperor. The test speed used was $36 \mathrm{~mm} / \mathrm{s}$. The tensile test results are presented in the charts in Figure 10. 


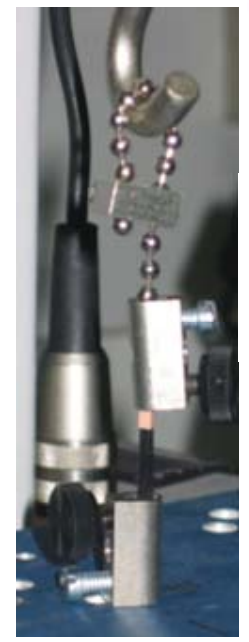

Tensile test

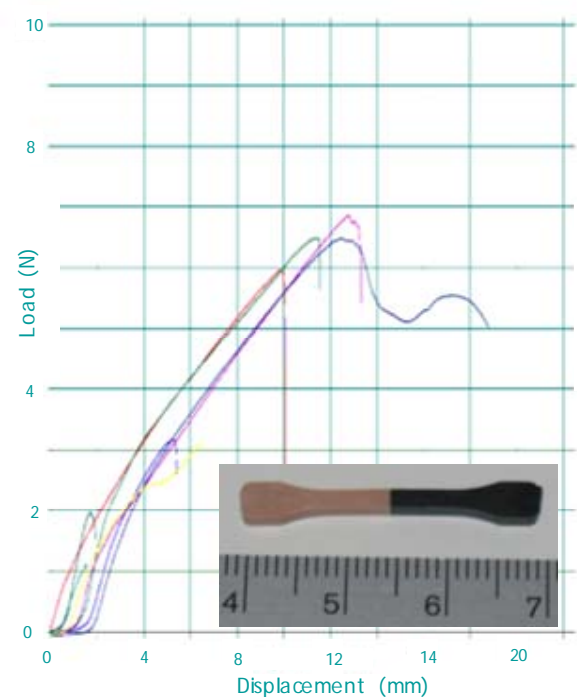

Sequential moulding

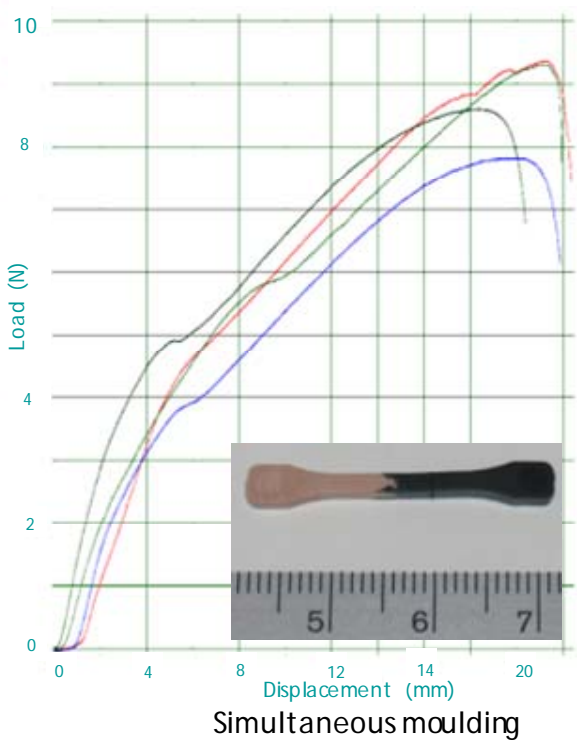

Simultaneous moulding

Figure 10: Schematic representation and dimensional specifications of new socket design based on $2 \mathrm{k}$ production concept.

Having an elastomeric material in the $2 \mathrm{k}$ combination is advantageous from bonding point of view [6]. This is because the elastomeric material absorbs some energy during the elastic deformation process before it starts to break at the interface. In the current case, the average bond strength was about 1.6 MPa for sequential moulding. In the second case of simultaneous injection moulding the average bond strength found was about $2.15 \mathrm{MPa}$. The reason for higher bonding in this case is the sufficient melting and mixing of the two materials together during $2 \mathrm{k}$ moulding. But the scenario of moulding $2 \mathrm{k}$ socket is close to the sequential moulding of the tensile bar that means the bonding between the sealing ring and socket house would be in the range of $1.6 \mathrm{MPa}$. The tensile strength of TPE Thermolast is $3.5 \mathrm{MPa}$ [7]. The bonding obtained in the $2 \mathrm{k}$ moulded socket house is about half of the strength of the TPE material. This bonding is quite acceptable for the current case because the interface of sealing ring and socket house does not have to withstand high mechanical force- bonding is just to make sure that the sealing ring does not fall out automatically from the socket house in the injection moulding stage and also during the use stage.

\subsection{Sealing test}

One of the most important functions of the newly moulded socket house is to provide sealing for the inside metallic components. To characterise the sealing property of the moulded sealing ring a test rig was developed. It consisted of two heavy brass plates for clamping the socket house. One brass plate had two guide pins and the other one had two corresponding holes for the alignment and clamping of the two brass plates. The plate with the guide pins had a small hole in the centre matching the dimension of the socket. Before the socket was inserted with the integrated sealing ring facing upwards, a standard sealing ring is inserted to ensure the tight sealing between the socket and plate. After the insertion of the socket in the cavity, the second brass plate was mounted. The moulded sealing ring provided sealing between the second plate and socket house. The top plate had an inlet for water. The water pressure could be applied inside the socket through a small hole. The manometer connected to the top plate could read the pressure developed inside the socket house. Figure 11 shows the components of the test rig and Figure 12 shows the test setup along with test results. 


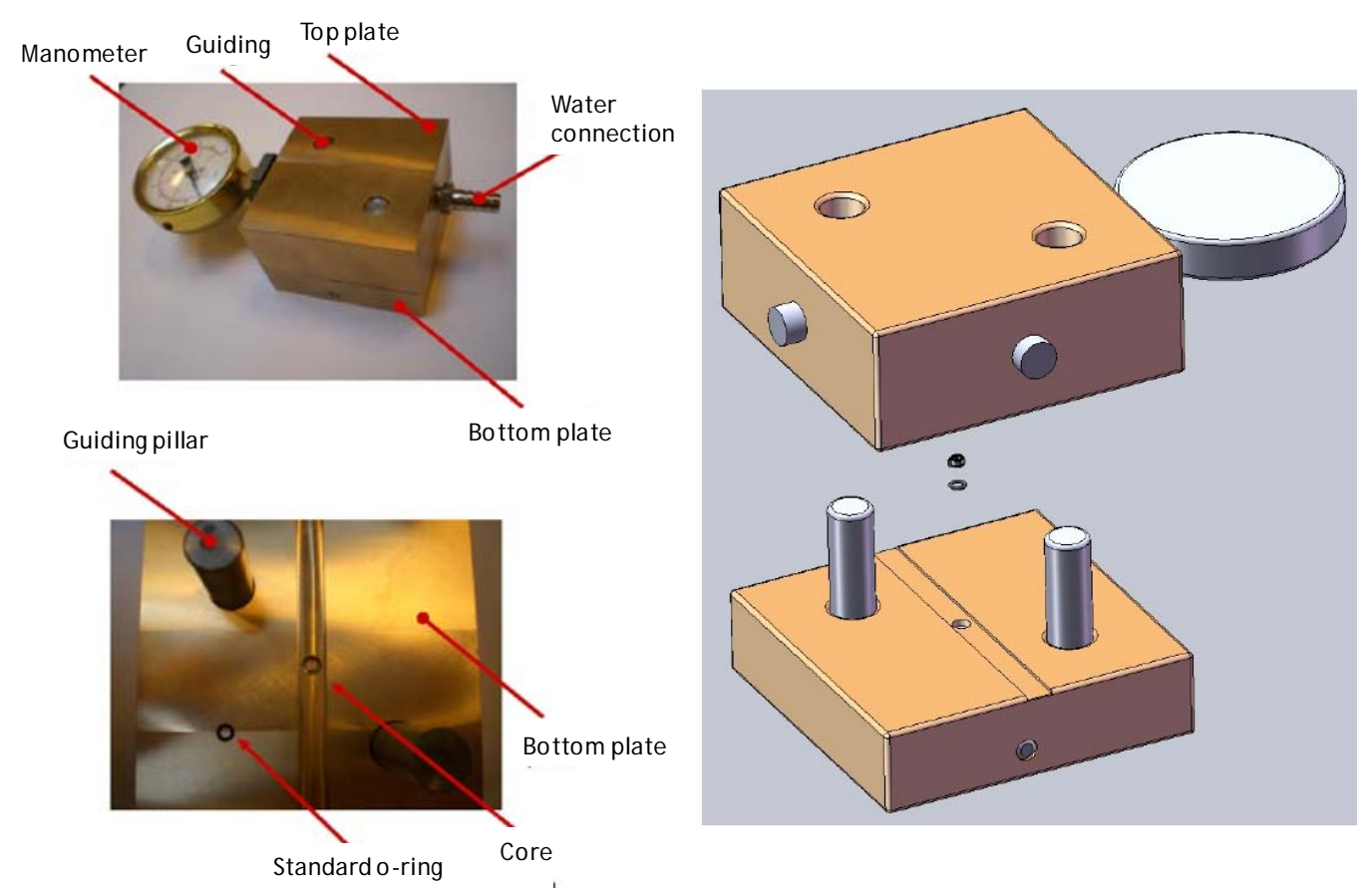

Figure 11: Schematic representation of the newly developed sealing tester for RIC socket.
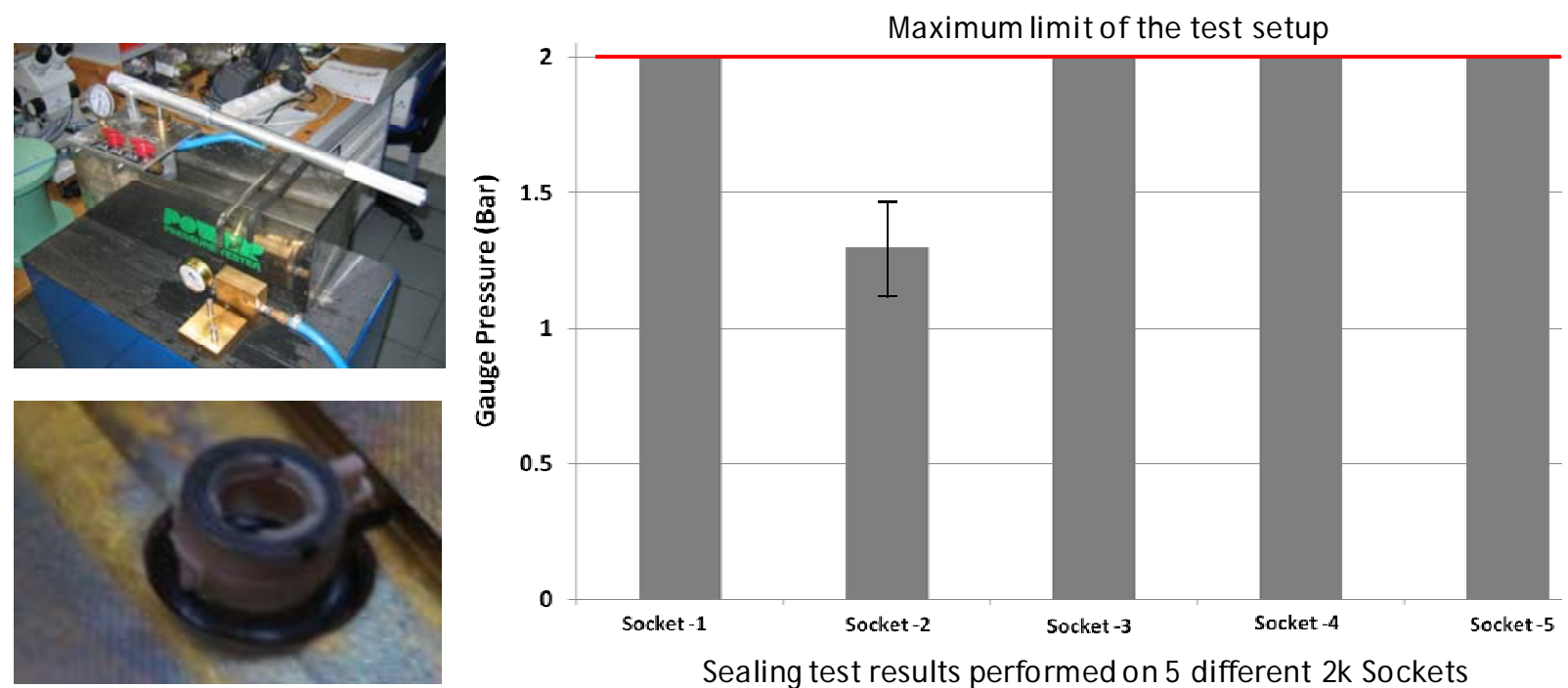

Figure 12: Schematic representation of sealing test and test results performed on 5 different $2 k$ sockets.

Samples were taken randomly for the test. The gauge pressure was recorded before the start of leakage of water. In most cases the sealing ring could withstand at least 2 bar of gauge pressure. After 2 bar in the manometer, the pumping was stopped due to the leakage problem in the manometer screw. In total five sockets were tested. The results are presented in Figure 12. All sockets could withstand at least 1 bar of gauges pressure; most of them could resist 2 bar. Only one failed before reaching 2 bar. Nonetheless, 1 to 2 bar of gauge pressure is a good result because the sealing ring does not have to resist any pressure above atmospheric pressure. When the socket is mounted at the hearing aid, there will also be atmospheric pressure both inside and outside the socket house. So if the sealing rings can withstand even 1 bar of guess pressure that is acceptable for this hearing aid application [8]. 


\section{Discussion and summary}

The investigation conducted in the current paper proved the feasibility of producing the new socket house with an integrated sealing ring by micro two component injection moulding. The use of the formicaPlast from DESMA makes the production process faster and convergent by eliminating the need for handling and assembly of micro parts like the small sealing rings. The chosen material pair (Ultramid PA-TPE Thermolast) from several options shows potential for hearing aid application both from product and process point of views.

One concern is the long term sealing behavior of the sealing ring material. Elastomeric materials lose their sealing property over time due to the material creep. But this depends on the compression set of Elastomeric material and in the current case the chosen material TPE Thermolast has relatively lower compression set compared to other available material. That means the material will recover well from the compression loading and this will ensure that the sealing rings retain their sealing properties over a longer period of time.

In the injection moulding there was problem with flash, especially with most of the TPE materials. Another problem with TPE materials were the tunnel gates in the mould. In some cases like TPE Lifoflex, the shear deformation caused in the tunnel gate during the part ejection was too high, and the bond between the TPE material and the PA socket was too weak. As a consequence, the sealing ring was pulled out of the socket. De-gating TPE material was another problem. Tunnel gate usually facilitate the automatic de-gating of the sprue form the part but in case of TPE the shear deformation does not allow a smooth break in the connection of the gate and the part. A smart redesign of the tunnel gate or using another gate type might improve the situation. A cutting mechanism can be introduced in the gate so that the TPE materials will be cut in the gate instead of breakage during the part ejection.

\section{Future work}

In the current work the short term sealing properties has been tested. The sealing properties of elastomeric materials changes over the time. Future work will focus on testing the long term sealing properties and to find the ways to simulate long term sealing behaviors in an accelerated test method. The boding between sealing ring and socket house can also be changed over the time due to the environmental conditions like humidity, sweat and thermal cycle etc. Investigation will be carried out to find the effects of these environmental conditions on the bonding and also on the sealing properties of the sealing ring.

Future work is also focused on next generation of RIC connectors. Different hearing aids require different number of pins in the RIC socket. The goal of future research is to provide a generic RIC socket and to establish the product platform so it can be possible to provide customized RIC solutions to the hearing aid manufacturers regardless the number of pins they require in the sockets. There is huge potential to increase the functionalities of the RIC socket by increasing the number of connection pins in the system. For example it can combine the functionalities of the RIC socket and the Programming socket in the same unit. It can facilitate simultaneous programming of the hearing aid while getting feedback from the user. Adding more than one receiver in the same ear canal for superior sound quality and also to incorporate more hearing aid 
components - like microphone or on-off switch or volume control with the same socket base can be facilitated with the additional number of contact pins in the socket. While providing more functions and features, the future RIC connector will still ensure the required sealing between the plug and socket utilizing a sealing ring to protect all the inner metallic components.

\section{Conclusion}

Two component injection moulding is an industrially important process technique; on the other hand it is a relatively complex process. But the right design of the part, wise material selection and optimized process parameters in state-of-the-art machine make it possible to produce micro $2 \mathrm{k}$ parts for precision applications. The investigation conducted with this paper showed the potential of the technology for moulding sealing ring for RIC applications. The characterization showed that the produced $2 \mathrm{k}$ parts could meet the technical requirement imposed on them by hearing aid applications. Nevertheless some other issue like long term sealing behaviour of the sealing ring, environmental effects on sealing and bonding quality should be investigated before finally introducing the $2 \mathrm{k}$ socket hearing aid application.

\section{Acknowledgement}

This paper reports work undertaken in the context of the project "COTECH-Converging Technologies for Micro System Manufacturing". COTECH is a Large Scale Collaborative Project supported by the European Commission in the $7^{\text {th }}$ Framework Programme (CP-IP 214491-2). Klöckner DESMA, Bremen-Germany, is acknowledged for their support and access to FormicaPlast $2 \mathrm{k}$ machine.

\section{References}

[1]. A. Islam, H.N. Hansen, P.T. Tang, M. Bondo, "Experimental investigation of the factors influencing polymer-polymer bond strength during two-component injection moulding"- International Journal of Advanced Manufacturing Technology, IJAMT (ISSN: 0268-3768) (DOI: 10.1007/s00170-009-2507-8), 2010, Springer U K. DOI 10.1007/s00170-009-2507-8.

[2]. M. Feeley, W.J. Staab,"RIC/RITE Technology", Advance for Hearing Practice Management-online issue, Vol.11, Issue 1, 2009.

[3]. Parker O-Ring Handbook, ORD 5700, Parker Hannifin Corporation, 2007.

[4]. Dipl.-Ing. Bjoern Dormann "2k-Micro Injection molding with FormicaPlast Industrial solution for precise mass production of micro parts" Polymer Process Engineering 09, ISBN 139871851432622.

[5]. Product Brochure- Formica Plast 2k, DESMA TEC, Desmastrasse 3/5, 28832 Achim, Germany.

[6]. H.R Brown, “Adhesion between polymers". IBM J. Res. Develop. Vol 38. No 4. July 1994 (pages 379-387).

[7]. Kraiburg TPE Datasheet-Compound TC5PCZ, KRAIBURG TPE GmbH \& CO, Germany, 2010.

[8]. A. Islam, H. N. Hansen, M. Marhöfer ${ }^{1}$, M. Bondo, "A new pair of hard-soft plastic combination for precision manufacturing of two component plastic parts", Proceedings from the $11^{\text {th }}$ International Conference of the European Society for Precision Engineering \& Nanotechnology, $23^{\text {rd }}$ May-27 $7^{\text {th }}$ May 2011, Lake Como, Italy. Volume 2, Page 184-187, ISBN 13: 987-0-9553082-9-1. 